\title{
Clinical significance of positive inotropic action of digoxin in patients with left ventricular disease
}

\author{
C. Davidson ${ }^{1}$ and D. Gibson ${ }^{2}$ \\ From the Department of Cardiology, St. Bartholomew's Hospital, London
}

Oral digoxin was administered for Io days to 9 patients with aortic Starr-Edwards prostheses. Its effect on the initial phase of left ventricular ejection was measured using a phonocardiographic method reflecting the initial acceleration of blood into the ascending aorta, and was correlated with plasma levels of the drug. $A$ positive inotropic effect was present, maximum 4 to 6 hours after first administration. The response was not correlated with the plasma levels which reached a peak at 2 to 3 hours. The magnitude of the effect was approximately one-third of that produced by mild supine exercise, and in individual patients there was close correlation between the effects of the two positive inotropic stimuli, suggesting variation in responsiveness from one patient to another. No significant positive inotropic effect attributable to digoxin could be demonstrated later in the study though plasma levels of the drug were within the therapeutic range throughout.

It was concluded that the positive inotropic effect of digoxin in these patients with left ventricular disease was small, compared with that of mild exercise. Chronic digoxin administration did not appear to cause a significant increase in left ventricular contractility. A concomitant reduction in sympathetic activity may be responsible for masking an inotropic effect in patients with intact cardiovascular reflexes, and could also play a part in producing a fall in venous pressure after digoxin.

Digitalis preparations are widely used in the treatment of heart disease. Their therapeutic action in patients in sinus rhythm is usually attributed to a positive inotropic action which has frequently been demonstrated in man, both at cardiac catheterization (Mason and Braunwald, 1963), and by such externally measured variables as left ventricular ejection time and pre-ejection period (Weissler et al., 1966; Shapiro, Narahara, and Taubert, 1970; Weissler and Schoenfeld, 1970). It was the purpose of the present study to document this positive inotropic effect after the administration of digoxin in therapeutic doses to patients with left ventricular disease, and to correlate the results with plasma levels of the drug measured by radioimmunoassay. Observations were made in patients with aortic Starr-Edwards prostheses (Gibson, Broder, and Sowton, 1970), allowing changes in left ventricular function due to digoxin to be assessed phonocardiographically over a period of ro days' continuous treatment and

Received 19 April 1973.

1 Present address: Department of Medicine, The General Infirmary, Leeds, Yorkshire.

2 Present address: Department of Cardiology, Brompton Hospital, London SW3 6HP. to be compared with those of mild, supine exercise in the same individual.

\section{Patients}

\section{Subjects and methods}

Clinical details of the 9 patients who took part in the study are given in Table 1 . All had isolated aortic valve disease, which had been treated by aortic valve replacement with a Starr-Edwards prosthesis at St. Bartholomew's Hospital in the previous 2 weeks to 3 years, and all were in sinus rhythm. None had had any digitalis preparation over the preceding 6 weeks, though maintenance diuretic treatment, required in 4 patients, was not interrupted for the study. All the patients had normal blood urea values. One patient (Case 2) was in pulmonary oedema throughout the acute study, and a further one developed atrial fibrillation during the chronic study (Case 5). The results from these 2 patients were not included in the analysis of the chronic study, which was therefore based on the 7 patients whose cardiac status remained stable throughout. The nature and purpose of the investigation were explained to the patients, and their consent obtained. There were no side effects.

\section{Phonocardiographic observations}

Phonocardiograms were recorded with Sanborn equipment, using a high-frequency filter system. The micro- 


\begin{tabular}{|c|c|c|c|c|c|c|}
\hline \multirow[t]{2}{*}{ Case No. } & \multirow[t]{2}{*}{$A g e(y r)$} & \multirow{2}{*}{$\begin{array}{l}\text { Aortic valve } \\
\text { replacement } \\
\text { (mth previously) }\end{array}$} & \multicolumn{2}{|c|}{ Chest x-ray } & \multirow[t]{2}{*}{$E C G$} & \multirow{2}{*}{$\begin{array}{l}\text { Diuretic } \\
\text { treatment }\end{array}$} \\
\hline & & & $\begin{array}{l}C T R \\
(\%)\end{array}$ & $\begin{array}{l}\text { Pulm. vasc. } \\
\text { congestion }\end{array}$ & & \\
\hline \multicolumn{7}{|l|}{ Female } \\
\hline I & 62 & 14 & $6 I$ & + & LVH & Nil \\
\hline 2 & 58 & 0.5 & 54 & ++ & LVH & Frusemide \\
\hline \multicolumn{7}{|l|}{ Male } \\
\hline 3 & 65 & 48 & 58 & 0 & $\begin{array}{l}\text { LBBB } \\
\text { PR } 0.22\end{array}$ & Nil \\
\hline 4 & 51 & 0.5 & 53 & 0 & LVH & Nil \\
\hline 5 & 53 & 3 & 46 & 0 & LVH & Bendrofluazide \\
\hline 6 & 43 & 18 & 48 & + & LVH & Nil \\
\hline 7 & 66 & 72 & 53 & + & $\overline{\mathrm{LVH}}$ & Frusemide \\
\hline 8 & 40 & 3 & 52 & 0 & LVH & Frusemide \\
\hline 9 & 42 & 0.5 & 49 & 0 & LVH & $\mathrm{Nil}$ \\
\hline
\end{tabular}

* Pulmonary vascular congestion: + , dilated upper lobe vessels, ++ additional lymphatic lines and intestitial oedema.

LVH, Left ventricular hypertrophy.

CTR, Cardiothoracic ratio, measured from PA chest radiograph.

phone was placed in the position down the left sternal edge where the clicks of the prosthesis were most clearly audible, and, in addition, during the control period, an indirect carotid pulse record was taken using a Phillips differential transformer. It was not possible to obtain technically satisfactory recordings of the carotid pulse during exercise. Phonocardiogram, electrocardiogram, and carotid pulse were recorded photographically at a paper speed of $100 \mathrm{~mm} / \mathrm{sec}$ using an SE 2005 ultraviolet recorder. A representative record is shown in Fig. I. $R R$ interval was measured from successive $R$ waves on the electrocardiogram. Since the exact origin of the $q$ wave was difficult to determine on account of somatic tremor, $\mathbf{Q A}_{1}$ interval was measured as the time between the most prominent part of the $R$ wave and the first high frequency component of the opening sound of the prosthesis $\left(A_{1}\right)$, to which was added the $\mathrm{qR}$ interval, determined from ro successive beats, at rest. Measurement of the $\mathrm{QA}_{1}$ interval in this way was found to give more reproducible values during exercise. Ejection time was measured as the interval between the onset of the rapid upstroke of the carotid pulse and its incisura, and ball travel time as ejection time less $A_{1} A_{2}$ interval. These measurements are indicated in Fig. I (Gibson et al., I970). In all cases, mean values from Io successive beats were used.

\section{Control values}

Control measurements were made at 9 a.m., noon, and 5 p.m. on the day before the acute study, as well as immediately before the first dose of digoxin. There were no consistent differences between values taken at these times, so that the control value for each patient was taken as the average of the four readings.

\section{Effect of exercise}

After the control measurements had been taken, at 9 a.m. on the day before the acute study, the patients performed straight leg raising, at a rate of approximately 60 times a minute, for a period of two minutes, and phonocardiogram and electrocardiogram were recorded at the end of this period. The aim was to increase the heart rate by about to beats a minute, and all the patients were able to manage this exercise without difficulty.

\section{Acute study}

This was designed to document the effects on heart rate and $\mathrm{QA}_{1}$ interval of a single oral dose of digoxin. After control measurements had been made, the patients took I mg digoxin at 9 a.m., and further records were made at Io a.m., II a.m., I p.m., and 3 p.m. and 5 p.m. Blood samples were taken, without occlusion, immediately after the phonocardiograms had been performed. Patients remained in bed throughout the acute study.

\section{Chronic study}

This was designed to assess the effect of more prolonged oral treatment with digoxin at a dose of $0.25 \mathrm{mg}$ three times daily, a dose commonly used in clinical practice. Measurements were made on alternate days. Phonocardiograms were recorded at 9 a.m. before the patients had risen, and digoxin was taken at 9.30 a.m., 2 p.m., and 8 p.m. As in the acute study, blood for digoxin levels was taken immediately after the phonocardiogram had been performed and therefore at least 12 hours after the last dose of digoxin. The chronic study was started on the day after the acute study had been completed. 


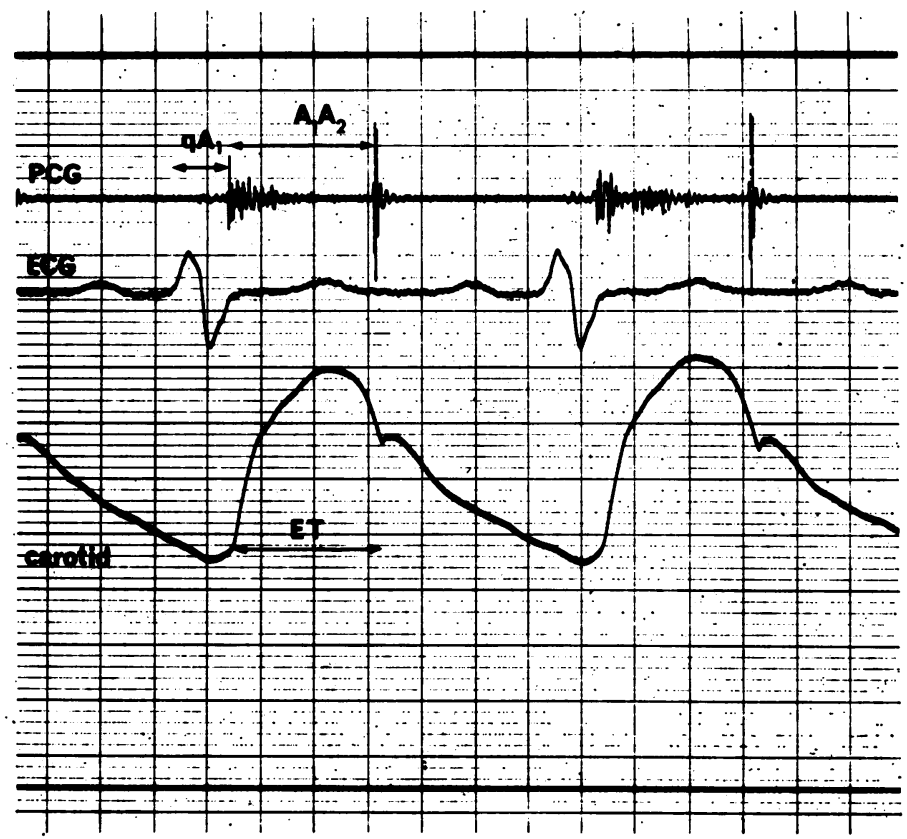

FIG. I Record of electrocardiogram (ECG), phonocardiogram (PCG), and indirect carotid pulse, indicating measurements made. ET, left ventricular ejection time; time marker 0.1 sec.

\section{Digoxin assay}

This was by radio immunoassay, using methods previously reported from this laboratory (Chamberlain et al., 1970). All samples were estimated in duplicate, the mean difference between duplicate determinations being 0.2 $\mathrm{ng} / \mathrm{ml}$.

TABLE 2 Analysis of variance: acute study

\begin{tabular}{lccll}
\hline $\begin{array}{l}\text { Source of } \\
\text { variance }\end{array}$ & $\begin{array}{l}\text { Sum of } \\
\text { squares }\end{array}$ & $\begin{array}{l}\text { Degrees of } \\
\text { freedom }\end{array}$ & $\begin{array}{l}\text { Variance } \\
\text { estimate }\end{array}$ & $F$ \\
\hline Patients & Ir91 & 8 & 149 & $5 \cdot 32 \dagger$ \\
Times & 410 & 4 & 103 & $3 \cdot 68^{\star}$ \\
Residuals & 887 & 32 & 28 & \\
Total & 2488 & 44 & & \\
& & & &
\end{tabular}

$\star \mathrm{P}<0.05$.

$+P<0.01$.

TABLE 3 Analysis of variance: chronic study

\begin{tabular}{lcccc}
\hline $\begin{array}{l}\text { Source of } \\
\text { variance }\end{array}$ & $\begin{array}{l}\text { Sum of } \\
\text { squares }\end{array}$ & $\begin{array}{l}\text { Degrees of } \\
\text { freedom }\end{array}$ & $\begin{array}{l}\text { Variance } \\
\text { estimate }\end{array}$ & $F$ \\
\hline Patients & 1575 & 6 & 262 & $5 \cdot 8 \dagger$ \\
Times & 168 & 5 & $33 \cdot 6$ & NS \\
Residuals & 1353 & 30 & $45 \cdot 1$ & \\
Total & 3096 & 41 & & \\
\hline
\end{tabular}

$+P<0.01$

\section{Statistical analysis}

This was by an analysis of variance. The statistical significance of reductions in $\mathbf{Q A}_{1}$ interval with respect to control at each time interval after administration of digoxin in the acute study, or on each day in the chronic study, was assessed from the residual variance estimate, using Student's ' $t$ ' test. The individual effects of $R R$ interval, and plasma digoxin level in predicting $\mathrm{QA}_{1}$ interval in each patient, were assessed by multiple

TABLE 4 Effect of $R R$ interval and digoxin level on $Q A_{1}$ : acute study $Q A_{1}$ a(dig. level $)+b(R R$ interval $)$ $+c$.

\begin{tabular}{lccccc}
\hline Case No. & $a$ & $b$ & $c$ & $S E_{a}$ & $S E_{b}$ \\
\hline $\mathrm{I}$ & $-\mathrm{I} .02$ & $+0.13^{\star}$ & +23.3 & 5.00 & 0.042 \\
2 & +2.72 & +0.11 & +52.0 & 5.60 & 0.10 \\
3 & +0.19 & $+0.14^{\star}$ & +67.9 & 3.17 & 0.064 \\
4 & -2.22 & +0.14 & +3.7 & 1.37 & 0.072 \\
5 & +13.77 & $+0.18 t$ & +2.5 & 6.52 & 0.043 \\
6 & +0.03 & +0.09 & +33.2 & 2.86 & 0.016 \\
7 & +0.56 & $+0.23^{\star}$ & -89.2 & 4.77 & 0.082 \\
8 & -4.37 & +0.06 & +39.6 & 4.86 & 0.042 \\
9 & +1.56 & +0.08 & +41.9 & 9.22 & 0.039 \\
\hline
\end{tabular}

SE, standard error.

$\star P<0.05$.

$+P<0.01$. 
TABLE 5 Effect of $R R$ interval and digoxin level on $Q A_{1}$ : chronic study

\begin{tabular}{lccccc}
\hline Case No. & $a$ & $b$ & $c$ & $S E_{a}$ & $S E_{b}$ \\
\hline $\mathbf{I}$ & -0.72 & $+0.14 \dagger$ & +35.0 & 3.82 & 0.036 \\
3 & -0.65 & +0.15 & 61.6 & 4.73 & 0.085 \\
4 & -9.23 & -0.027 & +112.7 & 3.10 & 0.046 \\
6 & -0.78 & $+0.099 \dagger$ & +31.1 & 1.55 & 0.007 \\
7 & +1.65 & $+0.22 \dagger$ & -78.0 & 5.82 & 0.066 \\
8 & +1.67 & $+0.14^{\star}$ & -14.9 & 4.73 & 0.051 \\
9 & +17.9 & +0.044 & +65.2 & 11.83 & 0.059 \\
\hline
\end{tabular}

$\star \mathrm{P}<0.05$.

$+\mathrm{P}<0.01$.

regression analysis for the acute and chronic studies separately. The results were expressed in the form

$$
\mathrm{QA}_{1}=\mathrm{a} \text { (digoxin level) }+\mathrm{b}(\mathrm{RR} \text { interval })+\mathrm{c},
$$

where $a, b$, and $c$ are constants. These, together with the standard errors of $a$ and $b$ and the probability of individual values differing from zero are shown in Tables 4 and 5. Statistical methods were those of Dixon and Massey (1969).

\section{Results}

\section{I) Effect of exercise}

Exercise caused a reduction in $\mathbf{Q A}_{1}$ interval in all patients, by a mean of $22 \mathrm{msec}$ (standard deviation 16) associated with an increase in heart rate from a mean of 87 to a mean of 97 beats per minute. Both changes were significant at the I per cent level.

\section{2) Acute study}

Digoxin levels Values of plasma digoxin, measured by radioimmunoassay, are shown diagrammatically as a function of the time after an oral dose of $\mathrm{I} \mathrm{mg} \mathrm{digoxin} \mathrm{in} \mathrm{Fig.} \mathrm{2.} \mathrm{The} \mathrm{peak} \mathrm{value} \mathrm{was} \mathrm{I} \cdot 4$ $\mathrm{ng} / \mathrm{ml}$, which was achieved after 2 hours, while by 8 hours the mean plasma level had dropped to 0.6 $\mathrm{ng} / \mathrm{ml}$.

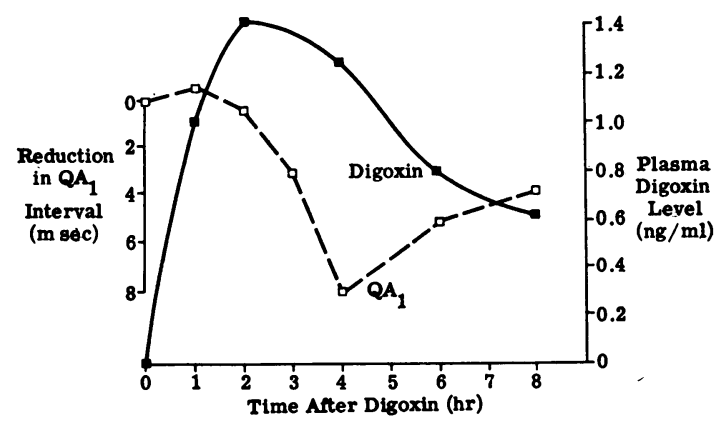

FIG. 2 Changes in $Q A_{1}$ interval and plasma digoxin level caused by oral administration of $I \mathrm{mg}$ digoxin. Mean values from 9 patients.
QA 1 interval Changes in $\mathrm{QA}_{1}$ interval are also shown in Fig. 2. A reduction of $8 \mathrm{msec}$ at 4 hours and $5 \mathrm{msec}$ at 6 hours are significant at the $\mathrm{I}$ and 5 per cent levels, respectively. The results of the overall analysis of variance are given in Table 2 .

Relation between $\mathbf{Q A}_{1}$ interval, $R R$ interval, and plasma digoxin level The results of multiple regression analysis in which the dependence of $Q A_{1}$ interval or $R R$ interval on plasma digoxin level were examined are given in Table 4 . In no patient was the coefficient ' $a$ ' significantly different from zero, indicating that $\mathrm{QA}_{1}$ interval was not determined to any significant degree by plasma digoxin level. In 4 patients, the coefficient ' $b$ ' differed significantly from zero, showing that in these subjects only, $\mathrm{QA}_{1}$ was dependent on heart rate.

Relation between digoxin and exerciseinduced changes in $\mathbf{Q} \mathbf{A}_{1}$ interval There was significant correlation between the reduction in $\mathbf{Q A}_{1}$ caused by digoxin and that due to exercise in the same patient (Fig. 3, r $=0.81, P<0.01$, standard error of the estimate $13 \mathrm{msec}$ ), the regression equation being: Exercise reduction of $\mathrm{QA}_{1}$ interval $(\mathrm{msec})=2 \cdot 83$ (digoxin reduction) $+2.6 \mathrm{msec}$.

In 2 of the patients, the greatest reduction in $\mathrm{QA}_{1}$ interval occurred after 6 hours, while in the remainder it was 4 hours after the initial oral dose. There was no significant correlation between the maximum change in $\mathrm{QA}_{1}$ interval due to digoxin and resting value of ball travel time $(r=0 \cdot I I)$.

Chronic study The results of the chronic study were analysed in the same way as those of the acute. The mean plasma level of digoxin was $I \cdot I \mathrm{ng} / \mathrm{ml}$, in specimens taken at least 12 hours after the last dose of digoxin. Throughout the study the $\mathrm{QA}_{1}$ interval did not differ significantly from control, the results

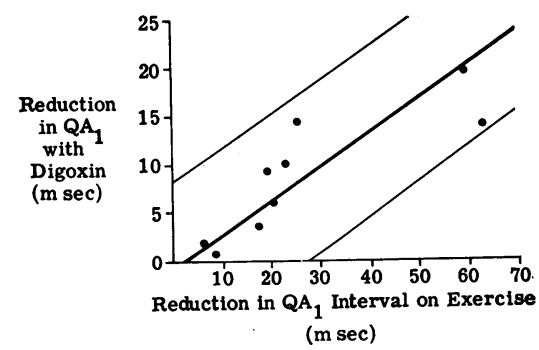

FIG. 3 Relation between reduction in $Q A_{1}$ interval caused by digoxin administration and that due to mild supine exercise in each of the 9 subjects. The regression line is indicated, together with limits set at 2 standard errors of the estimate. 
of the analysis of variance being given in Table 3. From the residual variance estimate, it is apparent that the minimum change in $\mathrm{QA}_{1}$ interval that would have differed significantly from control was $6 \mathrm{msec}$. The relation between $\mathrm{QA}_{1}$ interval, $R R$ interval, and plasma digoxin level is given in Table 5. In 4 patients rate-dependence of the $\mathrm{QA}_{1}$ interval was demonstrated, while in I (Case 4) $\mathrm{QA}_{1}$ interval was related to plasma digoxin level at the 5 per cent level of significance.

\section{Discussion}

Measurement of the interval between the $Q$ wave of the electrocardiogram and the opening sound of an aortic Starr-Edwards prosthesis $\left(\mathbf{A}_{1}\right)$ has proved a sensitive method of assessing changes in left ventricular function, reflecting the forces causing ejection of blood into the aorta (Gibson et al., 1970). It is relatively unaffected by tachycardia induced by atropine administration, ventricular pacing, or changes in posture, while it is consistently reduced by positive inotropic stimuli such as exercise on post-ectopic potentiation, and increased by betaadrenergic blockade (Gibson, Broder, and Sowton, 1970, 1971 ; Crouchman, Gibson, and Hamer, 1972). Since the technique requires only an electrocardiogram and a phonocardiogram, frequent measurements can be made with little disturbance to the patient, and both short and long-term changes in ventricular function can be studied.

The demonstration of a positive inotropic stimulus may be influenced by a number of factors. In the presence of severe heart disease, the force generated by the left ventricle may be at a maximum under control conditions, and no further increase be possible, however strong the stimulus (Blinks and Koch-Weser, 1963). In order to demonstrate that the patients studied were capable of responding to a positive inotropic stimulus, a reduction in $\mathbf{Q A}_{1}$ interval was confirmed in all of them during mild exercise. Since changes in left ventricular function induced by alterations in end-diastolic fibre length do not appear to be wholly separable from those due to a change in contractile state (Pollack, 1970), it is possible that both might alter the $\mathrm{QA}_{1}$ interval. However, previous studies have indicated that the effects of changes in left ventricular filling are small (Gibson et al., 1970, 1971) and, in addition, if such changes did occur, they would be in the same direction as those caused by the positive inotropic action of digoxin on $\mathrm{QA}_{1}$ interval. A possible separate effect of heart rate was defined in each patient by multiple regression analysis and dissociated from that of plasma digoxin level. In 4 patients significant positive correlation was present between RR interval and $\mathrm{QA}_{1}$ interval, while in the remainder the two were independent. This difference may reflect the mechanism by which changes in heart rate were mediated, being by alterations in sympathetic rather than vagal activity in those patients in whom $\mathbf{Q A}_{1}$ interval shortened with tachycardia. Such lack of uniformity suggests that the use of correction factors derived from pooled data to normalize results may not always be valid, since the relation between sympathetic and parasympathetic influences may be disturbed in heart failure or digoxin administration.

The results of this study show a significant reduction in $\mathrm{QA}_{1}$ interval 4 to 6 hours after an oral dose of digoxin, indicating an increase in the force of left ventricular contraction. This occurred approximately 2 hours after peak plasma concentrations had been reached so that the delay probably reflected the time necessary for the drug to equilibrate between blood and myocardium. This accounts for the lack of correlation between plasma digoxin levels and the reduction in $\mathrm{QA}_{1}$ interval, and consequently in the chronic study, measurements were made at least 8 hours after the last dose of digoxin had been given to allow a steady state to be reached. The maximum change in ventricular function after oral digoxin was earlier in the study than in previous reports and resembled more closely those in which the drug had been given intravenously (Weissler et al., 1966; Shapiro et al., 1970). This suggests that the delay in the onset of the action of digoxin is due to its uptake by myocardium rather than to its absorption from the gut, a conclusion supported by experimental work (Deutscher, Harrison, and Goldman, 1972).

Although the reduction in $\mathrm{QA}_{1}$ interval occurring after digoxin was statistically significant, its absolute magnitude was small, being less than one-third that of mild exercise. This figure compares closely with experimental work, in which maximal therapeutic doses of digoxin increased left ventricular $\mathrm{dp} / \mathrm{dt}$ max of canine heart by 32 per cent above control, whereas an increase of 80 per cent could be achieved with isoprenaline (Beiser et al., 1970). In addition, the magnitude of the reduction in $\mathbf{Q A}_{1}$ interval caused by digoxin correlated with that occurring during exercise in the same patient, indicating that the response to one inotropic stimulus could be predicted from observing the response to another unrelated one, and that differences in sensitivity to inotropic stimuli were probably the basis of the between-patient variance demonstrated in the acute study. However, this correlation could, theoretically, have resulted from the technique itself, since the initial acceleration of the ball of the prosthesis and therefore the force generated by the left ventricle at the onset of ejection, is inversely proportional to the square of the ball travel time, the time 
taken by the ball to travel from the base to the apex of the cage. The greater the resting value of acceleration, the smaller the reduction in ball travel time for a given change in initial acceleration, so that the sensitivity of the method is correspondingly reduced. However, if the correlation between the effects of digoxin and those of exercise were solely due to this cause, the patients in whom the change in $\mathbf{Q A}_{1}$ interval was smallest would be expected to have the shortest values of ball travel time at rest, and this was not the case. It was concluded, therefore, that the between-patient variance was the result of real differences in the sensitivity of the myocardium to positive inotropic stimuli.

In contrast to the acute study, prolonged administration of digoxin was not associated with a statistically significant reduction in $\mathbf{Q A}_{1}$ interval below control values. This cannot be attributed to a concomitant increase in stroke volume, since this would, if anything, have caused a reduction in $\mathrm{QA}_{1}$ interval. It is unlikely to have been due to failure of absorption of the drug, since a clear-cut response occurred in the acute study when the drug was given orally, and, in addition, therapeutic blood levels were demonstrated throughout. It is possible that prolonged reduction did occur, but that the method used was too insensitive to detect it: however, the maximum value of an effect which would have been missed for this reason can be estimated from the residual variance estimate, and was of the order of $6 \mathrm{msec}$, less than one-third of the change caused by mild exercise. The overall suitability of the method, however, for documenting such changes, had they occurred, was confirmed by the significant effect demonstrated in the acute study. It is, therefore, possible that the effect of the drug was modified by the presence of intact reflexes, and that its positive inotropic effect was masked by a corresponding reduction in the level of endogenous sympathetic activity, so that the overall level of the left ventricular contractile state remained unchanged. Indirect evidence for such a reduction in sympathetic activity has been obtained from observations of the effect of ouabain on the peripheral circulation (Mason and Braunwald, 1964). In patients in heart failure its administration was associated with a reduction in forearm venous tone and peripheral resistance which could not be attributed to a direct effect of the drug, but which was possibly to be due to sympathetic withdrawal secondary to improved cardiac function. Though the afferent stimulus was not defined, it is likely from the relative magnitudes of the effects of exercise and digoxin observed in the present study that a diminution of sympathetic tone, however mediated, might mask the positive inotropic effect of digoxin.
The present results may also have relevance in the clinical setting. Digitalis preparations are frequently recommended in low cardiac output states for their effect of left ventricular function (Wood, 1962b). However, in doses commonly employed in clinical practice, the magnitude of their effect is likely to be small compared with that of sympathetic stimulation, showing that infusion of adrenaline or isoprenaline is a much more effective method of increasing the force of left ventricular contraction if this is thought to be indicated. Theoretically, a group of patients might exist in whom catecholamines are without effect, but who are still capable of response to digitalis; but by showing close correlation between the effects of digitalis and exercise, the present study gives no support to this idea.

The failure to demonstrate a consistent reduction in $\mathrm{QA}_{1}$ interval during chronic digoxin administration is in line with a previous study in which the effects of long-term digitoxin treatment were undetectable using a ballistocardiographic method (Starr and Luchi, 1969), and suggests that the use of digitalis preparations may not necessarily be associated with a sustained increase in left ventricular contractile state above control values. Such preparations would therefore resemble other positive inotropic stimuli such as isoprenaline (Gunnar et al., 1967; Mueller et al., I968) or paired pacing (King and Taylor, I968) where a long-term positive inotropic action may not be demonstrable due possibly to tachyphylaxis or to the effects of increased oxygen requirement on a diseased myocardium. The present results therefore raise the possibility that the therapeutic effects of digitalis in patients in sinus rhythm in causing, for example, diuresis or reduction in venous pressure (Wood, 1962a), may not be due to an increase in left ventricular contractile state. It is suggested, rather that they may result either from secondary reflex changes, in particular from a reduction in endogenous sympathetic activity, or from effects elsewhere in the cardiovascular system.

\section{References}

Beiser, G. D., Epstein, S. E., Goldstein, R. E., Stampfer, M., and Braunwald, E. (1970). Comparison of the peak inotropic effects of a catecholamine and a digitalis glycoside on the intact canine heart. Circulation, 42, 805.

Blinks, J. R., and Koch-Weser, J. (I963). Physical factors in the analysis of the actions of drugs on myocardial contractility. Pharmacological Reviews, 15, 531.

Chamberlain, D. A., White, R. J., Howard, M. R., and Smith, T. W. (1970). Plasma digoxin concentrations in patients with atrial fibrillation. British Medical fournal, 3 , 429.

Crouchman, M., Gibson, D., and Hamer, J. (1972). Actions of beta-adrenergic blocking drugs assessed in patients with aortic Starr-Edwards prostheses (abstract). British Heart fournal, 34, 963. 
Deutscher, R. N., Harrison, D. C., and Goldman, R. H. (1972). The relation between myocardial ${ }^{3} \mathrm{H}$-digoxin concentration and its hemodynamic effects. American fournal of Cardiology, 29, 47.

Dixon, W. J., and Massey, F. J., Jr. (1969). Introduction to Statistical Analysis, 3rd ed. McGraw-Hill, New York.

Gibson, D. G., Broder, G., and Sowton, E. (1970). Phonocardiographic method of assessing changes in left ventricular function after Starr-Edwards replacement of aortic valve. British Heart fournal, 32, 142.

Gibson, D. G., Broder, G., and Sowton, E. (1971). Effect of varying pulse interval in atrial fibrillation on left ventricular function in man. British Heart fournal, 33, 388.

Gunnar, R. M., Loeb, H. S., Pietras, R. J., and Tobin, J. R., Jr. (1967). Ineffectiveness of isoproterenol in shock due to acute myocardial infarction. Fournal of the American Medical Association, 202, I124.

King, A. J., and Taylor, D. E. M. (1968). The inotropic action of paired pulse stimulation in the normal and failing heart: an experimental study. Cardiovascular Research, 2, 122.

Mason, D. T., and Braunwald, E. (1963). Studies on digitalis IX. Effects of ouabain on the non-failing human heart. fournal of Clinical Investigation, 42, I 105.

Mason, D. T., and Braunwald, E. (1964). Studies on digitalis $X$. Effects of ouabain on forearm vascular resistance and venous tone in normal subjects and patients in heart failure. Fournal of Clinical Investigation, 43, 532.
Mueller, H., Gianelli, S., Ayres, S. M., Conklin, E. F., and Gregory, J. J. (1968). Effect of isoproterenol on ventricular work and myocardial metabolism in the postoperative heart. Circulation, 37, I I-I46.

Pollack, G. H. (1970). Maximum velocity as an index of contractility in cardiac muscle: a critical evaluation. Circulation Research, 26, III.

Shapiro, W., Narahara, K., and Taubert, K. (1970). Relationship of plasma digitoxin and digoxin to cardiac response following intravenous digitalization in man. Circulation, 42, 1065 .

Starr, I., and Luchi, R. J. (I969). Blind study on the action of digitoxin on elderly women. American Heart fournal, 78, 740 .

Weissler, A. M., and Schoenfeld, C. D. (1970). Effect of digitalis on systolic time intervals in heart failure. American Fournal of the Medical Sciences, 259, 4.

Weissler, A. M., Snyder, J. R., Schoenfeld, C. D., and Cohen, S. (I966). Assay of digitalis glycosides in man. American fournal of Cardiology, 17, 768 .

Wood, P. (1962a). Diseases of the Heart and Circulation, 2nd ed., p. 294. Eyre and Spottiswoode, London.

Wood, P. (1962b). Diseases of the Heart and Circulation, and ed., p. 749. Eyre and Spottiswoode, London.

Requests for reprints to Dr. C. Davidson, The General Infirmary, Leeds, Yorks. 